\title{
COMPARATIVE STUDY ON ACCEPTANCE CRITERIA FOR NON-DUCTILE REINFORCED CONCRETE COLUMNS
}

\author{
Opabola Eyitayo ${ }^{1}$ and Kenneth J. Elwood ${ }^{2}$
}

(Submitted June 2018; Reviewed September 2018; Accepted October 2018)

\begin{abstract}
Poor seismic performance of older reinforced concrete buildings in past seismic events has frequently been attributed to failure of non-ductile columns not detailed for seismic demands. The Seismic Assessment of Existing Buildings Guidelines developed in New Zealand (NZ Guideline) provides a performance-based engineering framework for assessment of existing buildings, with concrete buildings covered in section C5. This study compares the probable failure mode and deformation capacity assessed based on NZ Guideline, ASCE/SEI 41-13, and ASCE/SEI 41-17 with the results from quasi-static cyclic tests conducted on 52 rectangular and 13 circular reinforced concrete columns with reinforcement details similar to those of nonductile columns. Results indicate that the general curvature-based method of the NZ Guideline was not able to identify the observed failure mode but generally provides a conservative estimate of deformation capacity in comparison with ASCE/SEI 41-17. Based on the results of this study, a direct rotation-based acceptance criteria is proposed for NZ Guidelines. Also, slight modifications, to reduce conservatism, have been proposed for the curvature-based method.
\end{abstract}

\section{INTRODUCTION}

The vulnerability of older reinforced concrete columns without ductile detailing has led to the collapse of concrete buildings during earthquakes worldwide. Specifically, in New Zealand secondary 'gravity' columns designed prior to NZS 3101:1995, are vulnerable to brittle failure at low drifts due to lack of ductile detailing. Reinforcement detailing deficiencies have been identified as a key contributing factor to the collapse of CTV building in February 2011 [1]. The approval of the building amendment bill in 2017, which emphasises the need for Territorial Authorities to demand engineering assessment of buildings identified to be potentially earthquake-prone, has brought to the forefront the necessity for a simple but detailed seismic assessment procedure that can effectively predict the probable failure mechanism and deformation capacity of these vulnerable non-ductile buildings. While not compromising the reliability of predicted results, such a procedure should be straightforward and also not overly conservative so as to avoid unnecessary rehabilitation or unwarranted demolition. An effective assessment guideline must be based on knowledge gained from structural performance in previous seismic events, combined with empirical models and experimental evidence, while taking into consideration perceived risk factors and appropriate conservatism for desired performance objectives under various seismic hazards. To address this need, the Seismic Assessment of Existing Buildings Guidelines (NZ Guidelines) was released in July 2017 [2].

Part C of the NZ Guidelines provides a methodology that enables engineers to perform a detailed seismic assessment. The methodology requires assessment of load paths in a structure, determination of probable strengths, deformation capacities and failure mechanism of structural components, and prediction of the global response of the building to seismic hazard and consequent seismic rating of the building. The NZ Guidelines are focused on life safety as the primary objective. A life safety issue is assumed to arise when the ultimate capacity of the building or its components is exceeded with a failure mode that could give rise to a "significant life safety hazard". A significant life safety hazard is defined as: "a hazard resulting from the loss of gravity support of a member/element of the primary or secondary structure, or of the supporting ground, or of critical nonstructural items that would reasonably affect a number of people". The NZ Guideline defines the ultimate capacity as "the building's probable capacity to withstand earthquake actions and maintain gravity load support calculated by reference to the building as a whole and its individual elements or parts".

The ASCE/SEI 41 Standard [3]-[5], developed to assist engineers in the United States with seismic assessment of existing structures, provides a performance-based framework for comparison of probable deformation demands for different seismic hazards against probable deformation capacities for various performance levels. The ASCE/SEI 41 Standard was developed based on the FEMA 273 Guideline [6] and the FEMA 356 pre-Standard [7]. Updates have been made to the ASCE/SEI 41 Standard (2006, 2013 \& 2017) [3]-[5] to reduce the level of conservatism through incorporation of results from laboratory experiments and relevant reliability concepts in the development of modelling parameters and acceptance criteria [8]. For concrete columns, ASCE/SEI 41 uses modelling parameter $\boldsymbol{a}$ to measure plastic rotation at significant degradation of lateral strength, modelling parameter $\boldsymbol{b}$ to define plastic rotation at axial failure and modelling parameter $c$ to define the residual lateral strength of a component (Figure 1). In ASCE/SEI 41-17, acceptance criteria are defined as fractions of modelling parameters in order to produce plastic rotation limits for various performance objectives. ASCE/SEI 41 provides acceptance criteria for three performance levels namely immediate occupancy (IO), life safety (LS) and collapse prevention (CP). ASCE/SEI 41 defines Immediate Occupancy as "the post-earthquake damage state in which a structure remains safe to occupy and essentially retains its pre-earthquake strength and stiffness". This performance level 
is typically targeted for frequent earthquakes. The Life Safety level is defined as "the post-earthquake damage state in which a structure has damaged components but retains a margin against the onset of partial or total collapse". Collapse Prevention is defined as "the post-earthquake damage state in which a structure has damaged components and continues to support gravity loads but retains no margin against collapse". The CP performance level is typically targeted for rare seismic events, often referred to as Maximum Considered Earthquake (MCE). The latest edition, ASCE/SEI 41-17, reduces the degree of conservatism and inconsistencies in probabilities of exceedance that characterised its predecessor (ASCE/SEI 4113) by redefining modelling parameters to represent median estimates of experimental data and defining acceptance criteria through fixed probabilities of exceedance for various performance levels [9].

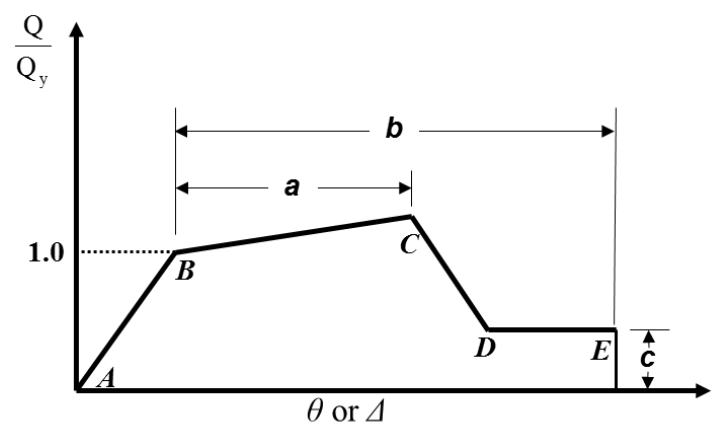

\section{Figure 1: Generalized force-deformation curve showing modelling parameters $a, b \& c$ [4].}

The aim of this study is to compare the probable failure mode and deformation capacity assessed based on the NZ Guideline (July 2017 version), ASCE 41-13, and ASCE 41-17 with the results from quasi-static tests conducted on 52 rectangular and 13 circular reinforced concrete columns with reinforcement details similar to non-ductile columns designed prior to implementation of NZS 3101:1995. This comparison allows for an objective assessment of the NZ Guideline provisions for concrete columns; recommended modifications to $\mathrm{C} 5$ based on this assessment are included. The scope of this paper is limited to assessment of probable failure mode and deformation capacity of reinforced concrete columns. No detailed information is provided on determination of seismic demands, analysis methodology, and assessment of global capacity.

\section{BEHAVIOR OF EXISTING NON-DUCTILE COLUMNS}

Post-earthquake reconnaissance reports [10], [11] from previous earthquakes around the world have detailed the poor performance of buildings with lightly reinforced concrete columns. Investigations of these buildings showed that the predominant cause of collapse was axial failure of gravity loading carrying components. Post-earthquake investigation and reports on buildings after the 2011 Christchurch earthquake [12], [13] detailed vulnerability of buildings with non-ductile gravity columns. These columns were not designed to contribute to the lateral load resisting system; however, under lateral deformation due to seismic excitations, gravity columns must be able to sustain their axial load capacity. Niroomandi et al. [14] investigated the history of existing concrete buildings and the evolution of design Standards for reinforced concrete columns in New Zealand. A comparison of NZS3101:1970P, 1982, 1995 and 2006 Standards showed that pre-1995 gravity columns, apart from gravity columns designed according to NZS 3101:1982 using a strength reduction factor $\phi$ of 0.9 , are vulnerable to brittle failures under seismic actions. Table 1 gives a summary of reinforcement detailing requirements for columns designed to the aforementioned NZS 3101 Standards. The Table gives a clear indication that gravity columns designed to NZS $3101: 1982$ using the reduction factor $\phi$ of 0.9 contain more transverse reinforcement than secondary columns designed to any of the other Standards.

In recent times, concerns have focused on the vulnerability of the gravity columns with reinforcement details that limit their ability to sustain high gravity loads while subjected to peak lateral deformation demands during an earthquake. Such reinforcement details include:

- Lack of confinement for concrete core and restraint for longitudinal reinforcement

- Poor transverse reinforcement anchorage (90 degree hooks)

- Wide spacing of transverse reinforcement ( $\mathrm{s} / \mathrm{d}>0.5)$

- Poorly confined column lap splices located in regions of maximum moment

- Plain round longitudinal bars (until the mid-1960s)

Such reinforcement deficiencies lead to undesirable failure modes in non-ductile columns. Potential failure modes of nonductile reinforced concrete columns include shear failure, flexural failure, and flexure-shear failure. A brief discussion on each failure mode is presented below:

Shear failure: In shear failure, the column experiences a brittle failure prior to flexural yielding. This failure occurs when the un-degraded shear strength is less than the shear demand at flexural strength. Brittle shear failure is characterised by diagonal cracking and it is often associated with columns with low aspect ratio (ratio of shear span to effective depth). Sheardamaged columns may possess axial capacity as a result of shear friction forces developed along the diagonal failure plane. For shear-damaged reinforced concrete columns under high axial load, loss of axial capacity may follow immediately after loss of lateral strength.

Flexure-shear failure: Flexure-shear failure is characterised by yielding of the column in flexure prior to failure in shear due to imposed flexural ductility demands that catalyse shear capacity degradation. As ductility demand increases, inclined cracks in concrete and degradation of aggregate interlock mechanism lead to degradation of the concrete contribution to shear capacity of the column. Sezen and Moehle [16] pointed out that concrete damage can also lead to loss of anchorage for transverse reinforcement and/or reduction in bond capacity for longitudinal and transverse reinforcement, thus degrading the truss mechanism as well.

Flexural failure: In a flexure-governed failure, degradation in the lateral load capacity occurs after the development of the column's flexural strength. Degradation in lateral strength and eventual loss of axial capacity is as a result of concrete spalling, longitudinal bar buckling due to lack of confinement for all longitudinal bars, poor anchorage and/or large spacing of transverse reinforcement, and concrete core crushing as a result of poor confinement without the formation of a diagonal failure plane (Figure 2).

\section{NZ GUIDELINES}

Section C5 of the NZ Guidelines provides the provisions for concrete buildings. The determination of deformation capacity in C5 is based on a general methodology which entails computation of probable capacities of structural components and determination of likely inelastic mechanism and deformation (drift) level at which the mechanism occur. The approach in the calculation of probable component capacity involves evaluation of probable flexural strength, shear strength using the modified UCSD shear model [17] and deformation capacities. The general procedure of $\mathrm{C} 5$ is presented in a flowchart format in Appendix A. 
Table 1: Transverse reinforcement detailing requirements for gravity columns according to NZS3101 (Adapted from [14]). See notations for definition of symbols.

\begin{tabular}{|c|c|c|c|c|}
\hline Reinforcement details & NZS 3101: 1970 & $\begin{array}{c}\text { NZS 3101:1982 } \\
\text { (Gravity columns) }\end{array}$ & $\begin{array}{c}\text { NZS 3101:1995 } \\
\text { (Gravity columns) }\end{array}$ & $\begin{array}{c}\text { NZS 3101:2006 } \\
\text { (Nominally ductile) }\end{array}$ \\
\hline $\begin{array}{c}\text { Maximum vertical } \\
\text { spacing of ties (s) }\end{array}$ & $\begin{array}{c}\text { Smallest of }\left(\mathrm{h}_{\min }, 16 \mathrm{~d} \mathrm{~b},\right. \\
\left.\text { or } 48 \mathrm{~d}_{\mathrm{s}}\right)\end{array}$ & $\begin{array}{c}\text { If } \phi=0.9: \text { smaller of } \\
\left(\mathrm{h} \text { min } / 5 \text { or } 6 \mathrm{~d}_{\mathrm{b}}\right) \\
\text { If } \phi=0.7: \text { Smallest of } \\
\left(\mathrm{hmin}, 16 \mathrm{~d}_{\mathrm{b}}, \text { or } 48 \mathrm{~d}_{\mathrm{s}}\right)\end{array}$ & smaller of $\left(\mathrm{h}_{\min } / 3\right.$ or $\left.10 \mathrm{~d}_{\mathrm{b}}\right)$ \\
\hline $\begin{array}{c}\text { Confinement } \\
\text { reinforcement (Ash) }\end{array}$ & - & $0.3 S_{h} h^{\prime \prime}\left(\frac{A_{g}}{A_{c}}-1\right) \frac{f_{c}^{\prime}}{f_{y t}}$ & $A_{s h}^{*}=\frac{\left(1-\rho_{L} m\right) S_{h} h^{\prime \prime}}{3.3} \frac{A_{g}}{A_{c}} \frac{f_{c}^{\prime}}{f_{y t}} \frac{N^{*}}{\varphi f_{c}^{\prime} A_{g}}-0.0065 S_{h} h^{\prime \prime}$ \\
\hline $\begin{array}{c}\text { Anti-buckling } \\
\text { reinforcement (Ate) }\end{array}$ & - & - & $\frac{\sum A_{b} f_{y}}{135 f_{y t}} \frac{s}{d_{b}}$ \\
\hline
\end{tabular}

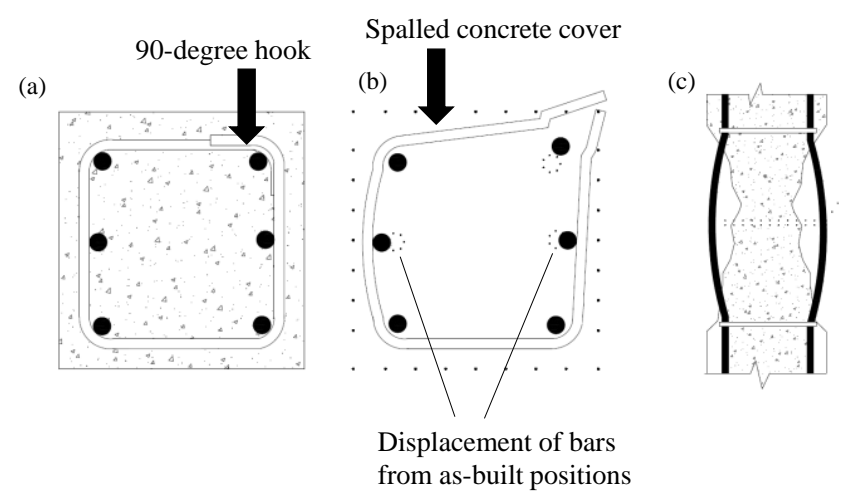

Figure 2: Potentially inadequate transverse reinforcement detailing: (a) Poor transverse reinforcement anchorage and lack of confinement for all longitudinal bars, (b) Poor details result into loss of confinement for concrete core and lack of support for longitudinal bars after concrete spalling, (c) Longitudinal bar buckling as a result of loss of support due to excessive transverse reinforcement spacing and/or hoop opening.

\section{Computation of Probable Flexural Strength and Deformation Capacity}

The probable flexural strength can be computed from the probable material strength using stress block theory and strain compatibility assumptions. Probable curvatures at effective yield and ultimate are calculated and then a bilinear momentcurvature relationship is plotted. C5 assumes that probable ultimate curvature is reached when the compressive strain at the extreme fibre is equal to $\varepsilon_{c, \text { max }}$. For unconfined concrete, $\varepsilon_{c, \max }$ is assumed to be 0.004 and for confined concrete, the expression presented by Paulay and Priestley [18] can be used in computing $\varepsilon_{c, \max }$ C5 assumes an unconfined condition if any of the following are present:

- transverse reinforcement spacing greater than half of the element's effective depth

- transverse reinforcement spacing greater than 16 times diameter of longitudinal reinforcement

- tie hooks are not properly anchored in the core (i.e. 90 degree hooks)

- only corner longitudinal bar are restrained by a bend of transverse reinforcement.

The probable first yield curvature corresponds to the point when the extreme tension reinforcement first attains yield strain, or when the extreme concrete compression fibre attains a strain of 0.002, which ever happens first [19]. C5 Guideline provides approximations for the computation of the equivalent yield curvature for different cross-sections. The general procedure for computation of probable flexural strength and deformation capacities is presented in Appendix A.

Section C1 of the NZ Guideline categorises a "lightly reinforced concrete column with axial loads greater $0.5 \mathrm{~A}_{g} f^{\prime} c$ " where failure of the column would lead to collapse of the entire storey as a Severe Structural Weakness (SSW). For all SSWs a factor of 0.5 is applied to calculation of the probable deformation capacities.

\section{Computation of Probable Shear Strength}

The probable shear strength is calculated using the modified UCSD model [17]. This shear model assumes strength contribution from concrete, transverse reinforcement, and axial load through arch action (See Appendix A). While the concrete contribution depends on ductility level, the model assumes the effectiveness of transverse reinforcement and arch mechanism from the axial load doesn't reduce with increasing level of ductility demand. The reduction in concrete effectiveness is taken into account through the degradation factor, $\gamma$. For uniaxial demands, $\gamma$ is defined to be equal to 0.29 for curvature ductility demand less than 3 , to be equal to 0.1 for curvature ductility demand greater than 15 , with linear interpolation for curvature ductility demand between 3 and 15 .

The magnitude of the axial load component is taken as the horizontal component of the diagonal compression strut (forming between the top and bottom of the column) that carries the axial load [20]. The angle of the diagonal compression strut to the longitudinal axis of the column is defined as $\alpha$.

\section{Flexure-Shear Capacity Interaction Curve}

According to $\mathrm{C} 5$, if the un-degraded shear strength is greater than the plastic shear demand, it is necessary to plot a flexureshear capacity interaction curve so as to capture shear strength degradation with increasing ductility demand and the possibility of the flexure strength-deformation curve 
intersecting the shear strength-deformation curve. The postyield failure mechanism could either be flexure-governed or flexure-shear governed. The probable failure mode is determined using the flexure-shear interaction curve. An intersection of flexure strength curve and shear strength curve before the yielding of the section signifies a probable shear failure mode while an interaction after yielding of the section signifies a probable flexure-shear failure (See Appendix A).

As previously stated, the UCSD shear strength model is used in developing the flexure-shear interaction curve in C5. This model, just like a number of other shear strength models [16] [21], [22], was developed for estimating the strength of a column as a function of deformation demands. Elwood \& Moehle [23] studied the effectiveness and reliability of shear strength models in the estimation of deformation capacity for a given shear demand - an approach adopted by C5 in the estimation of drift ratio at flexure-shear and shear failure modes. Using the Sezen \& Moehle shear strength model [16] and a dataset of 50 shear-critical reinforced concrete columns, the study showed that the strength ratio (defined as the ratio of measured shear strength to calculated shear strength) had a mean value of 1.06 with a coefficient of variation of $15 \%$. On the other hand, the mean drift ratio (defined as the ratio of measured drift ratio at lateral load failure to calculated drift ratio capacity) had a mean value of 1.78 with a $63 \%$ coefficient of variation. The study concluded that estimating deformation capacity using a shear strength model may be inappropriate.

\section{Ultimate Deformation Due to Onset of Longitudinal Bar Buckling}

Figure A4 (Appendix A) indicates two flexure failure modes are considered in the $\mathrm{C} 5$ procedure: flexure failure due to concrete crushing (when concrete strain reaches $\varepsilon_{c, \max }$ at end of flexural response curve - solid line in Figure A4, Appendix A) and flexure failure due to bar buckling (depicted with '*' symbol). C5 adopts the Berry \& Eberhard bar buckling model [24] to estimate the displacement at which longitudinal bar buckling may occur (Equation 1).

$$
\Delta_{u}=0.0325 L_{c}\left[1+k_{e b b} \rho_{e f f} \frac{d_{b}}{D}\right]\left[1-\frac{P}{A_{g} f_{c}^{\prime}}\right]\left[1+\frac{L_{c}}{10 D}\right]
$$

$\mathrm{k}_{\text {ebb }}=0$ for columns with $\mathrm{s} / \mathrm{d}_{\mathrm{b}} \geq 6$

$\mathrm{k}_{\text {ebb }}=40$ and 150 for rectangular columns and spiralreinforced columns with $s / d_{b}<6$, respectively.

Equation 1 provides an estimate of the median drift at which bar buckling occurs, with a coefficient of variation of $25 \%$ based on a database of 62 rectangular and 42 spiral-reinforced columns [24].

\section{Drift Ratio at Flexure-Shear Failure}

For columns expected to experience shear failure after flexural yielding, C5 adopts the Elwood \& Moehle drift at shear failure model [23]. The displacement at shear failure can be computed as:

$$
\Delta_{s}=L_{c}\left(0.03+4 \rho_{t}-0.024 \frac{v}{\sqrt{f_{c}^{\prime}}}-0.025 \frac{P}{A_{g} f_{c}^{\prime}}\right) \geq 0.01 L_{c}
$$

Equation 2 provides an estimate of the median drift at $20 \%$ loss in lateral load capacity for columns experiencing a flexure-shear failure, with a coefficient of variation of $34 \%$ based on a database of 50 shear-critical columns [23]. The text of C5 is not clear if the drift based on Equation 2 or the drift based on intersection of the flexural response curve and shear strength envelope (See Figure A4, Appendix A) should be used for the drift at flexure-shear failure.

It should be noted that while models for mean or median response (such as Equations 1 and 2) may be appropriate as modelling parameters, they may not be appropriate for acceptance criteria given the relatively large coefficient of variations arising from the simplicity of the empirical models and the complexity of the phenomenon. It is encouraged that acceptance criteria should be set, with desirable probabilities of exceedance, as fractions of estimates derived from medianbased models. Furthermore, the use of empirical models to assess structural components with properties dissimilar to those of the specimens used in the validation of the models may not be appropriate.

\section{ASCE/SEI 41-13}

ASCE/SEI 41-13 [4] establishes the deformation capacity of a column based on its probable failure mode. The probable failure mode is ascertained by comparing the probable plastic shear demand (shear force corresponding to development of flexural capacity) with un-degraded probable shear strength computed using the shear strength model developed by Sezen and Moehle [16]. Unlike the Sezen and Moehle model, ASCE/SEI 41-13 takes into consideration the effectiveness of widely spaced transverse reinforcement in resisting shear. ASCE/SEI 41-13 specifies that a 50\% reduction in the effectiveness of transverse reinforcement if the transverse reinforcement spacing exceeds half the component effective depth and the transverse reinforcement is considered ineffective if its spacing exceeds the primary effective depth (Equation 3).

$$
\begin{gathered}
V_{p r o b}(0)=\alpha_{c o l} \frac{A_{v} f_{y t} d}{s}+\lambda\left(\frac{0.5 \sqrt{f_{c}^{\prime}}}{M / V d} \sqrt{1+\frac{N}{0.5 \sqrt{f_{c}^{\prime}} A_{g}}}\right) 0.8 A_{g} \\
\alpha_{c o l}=1.0 \text { for } \mathrm{s} / \mathrm{d} \leq 0.5 ; 0.5 \text { for } 0.5<\mathrm{s} / \mathrm{d}<1 ; 0 \text { for } \mathrm{s} / \mathrm{d} \geq 1
\end{gathered}
$$

Based on the ratio of computed plastic shear demand $\left(\mathrm{V}_{\mathrm{f}}\right)$ to un-degraded shear strength $\left(\mathrm{V}_{\mathrm{prob}}(0)\right)$ and transverse reinforcement details, ASCE/SEI 41-13 classifies columns into different failure modes (Table 2). For a column to be classified as flexure-governed, its ratio of transverse reinforcement spacing to effective depth must not be greater than 0.5 , and transverse reinforcement ratio must not be less than 0.002 in the plastic hinge region.

Table 2: Classification of columns according to ASCE/SEI 41/13 [4].

\begin{tabular}{|l|l|l|l|}
\hline $\begin{array}{l}\text { Shear capacity } \\
\text { ratio }\end{array}$ & $\begin{array}{l}\text { ACI 318 } \\
\text { conforming } \\
\text { seismic } \\
\text { details with } \\
\text { 135-degree } \\
\text { hooks }\end{array}$ & $\begin{array}{l}\text { Closed hoops } \\
\text { with 90- } \\
\text { degree hooks }\end{array}$ & $\begin{array}{l}\text { Other } \\
\text { (including lap- } \\
\text { spliced } \\
\text { transverse } \\
\text { reinforcement) }\end{array}$ \\
\hline $\mathrm{V}_{\mathrm{f}} / \mathrm{V}_{\text {prob }}(0) \leq 0.6$ & Flexure & Flexure-shear & Flexure-shear \\
\hline $\begin{array}{l}1.0 \geq \mathrm{V}_{\mathrm{f}} / \mathrm{V}_{\text {prob }}(0) \\
\geq 0.6\end{array}$ & Flexure-shear & Flexure-shear & Shear \\
\hline $\mathrm{V}_{\mathrm{f}} / \mathrm{V}_{\text {prob }}(0)>1.0$ & Shear & Shear & Shear \\
\hline
\end{tabular}

Based on a column's predicted failure mode, ASCE/SEI 41-13 recommends modelling parameters $\boldsymbol{a}, \boldsymbol{b} \& \boldsymbol{c}$. ASCE/SEI 41-13 defines $\boldsymbol{a}$ as the plastic rotation at significant degradation of lateral strength (i.e. from yield up to $20 \%$ loss of lateral load capacity), parameter $\boldsymbol{b}$ is defined as the plastic rotation at onset of axial failure and parameter $c$ defines the residual lateral strength of a component (Figure 1). Given the scatter involved in the estimation of the modelling parameters, target probabilities of failure were established by taking into account consequence of each failure mode [8]. $\boldsymbol{a}$ values were selected 
to achieve probability of failure less than $35 \%$ for flexurecritical members and less than $15 \%$ for shear and flexure-shear critical members while probability of failure for $\boldsymbol{b}$ values, irrespective of failure mode, was set to less than $15 \%$. Target probabilities of failure are conditional upon the earthquake demand causing drifts exceeding the acceptance criteria, and ASCE/SEI 41 indicates that the true probability of failure of an existing building throughout its design life will be significantly lower, given the low probability of exceedance for commonly selected design ground motions [8].

Acceptance criteria for reinforced concrete columns are dependent on predicted failure condition, modelling parameters $(\boldsymbol{a} \& \boldsymbol{b})$, and desired performance level. Values of modelling parameters and acceptance criteria for different performance objectives are provided in Table 10-8 of ASCE/SEI 41-13 [4].

\section{ASCE/SEI 41-17}

Acceptance criteria for columns in ASCE/SEI 41-17 [5], unlike the ASCE/SEI 41-13, are equation-based. For columns not controlled by inadequate splicing, modelling parameters and acceptance criteria are computed based on the axial load ratio, transverse reinforcement ratio, and ratio of shear demand at flexural yielding to un-degraded shear capacity. Including $\mathrm{V}_{\mathrm{f}} / \mathrm{V}_{\text {prob}}(0)$ in the calculation of the drift capacity removed the necessity to categorise the failure mode of the column as done in ASCE/SEI 41-13. The equation for estimation of modelling parameter $\boldsymbol{a}$ was obtained through linear regression to represent a median estimate from experimental values in the ACI 369 column database [25]. The equation for modelling parameter $\boldsymbol{b}$ is based on a modification of the shear-friction failure capacity model developed by Elwood and Moehle [15] due to lack of adequate data to calibrate a regression model.

Li et al. [26] showed that the shear model adopted by ASCE/SEI 41-13 was too conservative and most flexure-shear critical columns are classified as shear critical by the 2013 model. In the interest of reducing the degree of conservatism in shear strength evaluation, ASCE/SEI 41-17 assumes a reduction in the effectiveness of transverse reinforcement in shear resistance only when the transverse reinforcement spacing exceeds three-quarter of the primary effective depth (Equation 4).

$V_{p r o b}(0)=\alpha_{c o l} \frac{A_{v} f_{y t} d}{s}+\lambda\left(\frac{0.5 \sqrt{f_{c}^{\prime}}}{M / V d} \sqrt{1+\frac{N}{0.5 \sqrt{f_{c}^{\prime}} A_{g}}}\right) 0.8 A_{g}$

$\alpha_{\mathrm{col}}=1.0$ for $\mathrm{s} / \mathrm{d} \leq 0.75,0.0$ for $\mathrm{s} / \mathrm{d} \geq 1.0$, and varies linearly for $\mathrm{s} / \mathrm{d}$ between 0.75 and 1.0.

For columns with rectilinear ties, not controlled by inadequate development or splicing along the clear height, ASCE/SEI 4117 defines modelling parameters $\boldsymbol{a}$ and $\boldsymbol{b}$ (Figure 1) as:

$$
a=0.042-0.043 \frac{N}{A_{g} f_{c}^{\prime}}+0.63 \rho_{t}-0.023\left(\max \left(\frac{V_{y}}{V_{o}}, 0.2\right)\right)
$$

(The value of $\boldsymbol{a}$ must be taken not less than zero)

$$
b=\left[\begin{array}{l}
\frac{0.5}{5+\frac{N}{0.8 A_{g} f_{c}^{\prime}} \frac{1}{\rho_{t}} \frac{f_{c}^{\prime}}{f_{y t}}}-0.01 \text { if } \frac{N}{A_{g} f_{c}^{\prime}} \leq 0.5 \\
0 \text { if } \frac{N}{A_{g} f_{c}^{\prime}}=0.7 \\
\text { linear interpolation if } 0.5<\frac{N}{A_{g} f_{c}^{\prime}}<0.7
\end{array}\right.
$$

(The value of $\boldsymbol{b}$ must be taken not less than the value of $\boldsymbol{a}$ )
As noted previously, while median estimates are appropriate for modelling parameters, it is prudent to select acceptance criteria with a lower probability of exceedance considering the relatively large coefficient of variations typical of empirical models for drift capacity. In ASCE 41-17, acceptance criteria were selected as $15 \%$ of the $\boldsymbol{a}$ values, but not greater than 0.005 , for Immediate Occupancy, $50 \%$ of the b values for Life Safety, and $70 \%$ of the $\boldsymbol{b}$ values for Collapse Prevention. The fractions of $\boldsymbol{b}$ values were selected to achieve low probabilities of axial failure for columns satisfying the acceptance criteria. These probabilities were $10 \%$ and $25 \%$ for Life Safety and Collapse Prevention, respectively.

\section{COLUMN DATABASE}

For this study, a dataset of reinforced concrete column tests were drawn from the ACI 369 database [25]. The ACI 369 database is a compilation of approximately 500 quasi-static reinforced concrete column (rectangular and circular) tests conducted worldwide. The database was developed to help facilitate updates to the concrete provisions of ASCE/SEI 41. The ACI 369 database provides information on geometric properties, sectional properties, force-displacement relations and other vital parameters for each column test.

With the intent of assessing how well C5 and ASCE/SEI 41 capture the failure of typical pre-1995 gravity columns in New Zealand, a set of column tests were selected from the ACI 369 database with the ratio of transverse reinforcement spacing to effective depth (s/d) similar to the detailing of pre-1995 gravity columns as reported by Niroomandi et al. [14]. A total of 52 rectangular columns with $\mathrm{s} / \mathrm{d} \geq 0.5$ and concrete compressive strength not greater than $50 \mathrm{MPa}$ were identified. However, only 11 circular column tests fit within the selection criteria. Only two additional column tests, on non-ductile circular columns, could be identified from other sources [27], [28]. Thus, making a total of 13 non-ductile circular columns in the dataset. Columns with lap splices were excluded from the dataset. The distributions of key parameters for rectangular and circular columns in the dataset are presented in Figures 3 $\& 4$ respectively and are summarised below:

- Aspect ratio (shear span to effective depth ratio):1.2 $\leq \mathrm{a} / \mathrm{d}$ $<9$

- Longitudinal reinforcement ratio: $0.9 \% \leq \rho_{\mathrm{L}} \leq 3.8 \%$

- Transverse reinforcement ratio: $0.03 \% \leq \rho_{\mathrm{t}} \leq 1.0 \%$

- Transverse reinforcement spacing to primary effective depth: $0.5 \leq \mathrm{s} / \mathrm{d} \leq 1.3$

- Axial load ratio: $0 \leq \mathrm{P} / \mathrm{Ag}_{\mathrm{g}}{ }^{\prime} c \leq 0.69$

Relating to failure modes of the rectangular column specimens reported in the database, 10 column specimens were reported to have failed in shear, 32 in flexure-shear, and 10 in flexure. For the circular column specimens, six were reported to be shear dominated, six were flexure-shear dominated and one was flexure dominated. The values of plastic rotation at lateral-load failure (i.e. $a$ from ASCE/SEI 41) and plastic rotation at axial-load failure (i.e. b from ASCE/SEI 41) were extracted from drift values provided by the ACI 369 database [24]. $a$ values were computed as difference between the drift (rotation) at which the lateral strength degraded by $20 \%$ from peak strength and drift (rotation) at yield. Rotation at yield was estimated by drawing a secant line, from the origin, to pass through the curve at $70 \%$ of maximum lateral load $\left(\mathrm{V}_{\max }\right)$ and made to intersect a horizontal line drawn at $\mathrm{V}_{\max }$. The drift at this intersection point was taken as the yield rotation [29]. Likewise, $b$ values were computed from values of rotation at the initiation of axial-load failure, if reported. Drift at axial failure was recorded in only eight tests. For columns tests where the axial failure was not reported, the database recorded the maximum drift reached during test or drift at which lateral strength degraded by $75 \%$ [26]. 

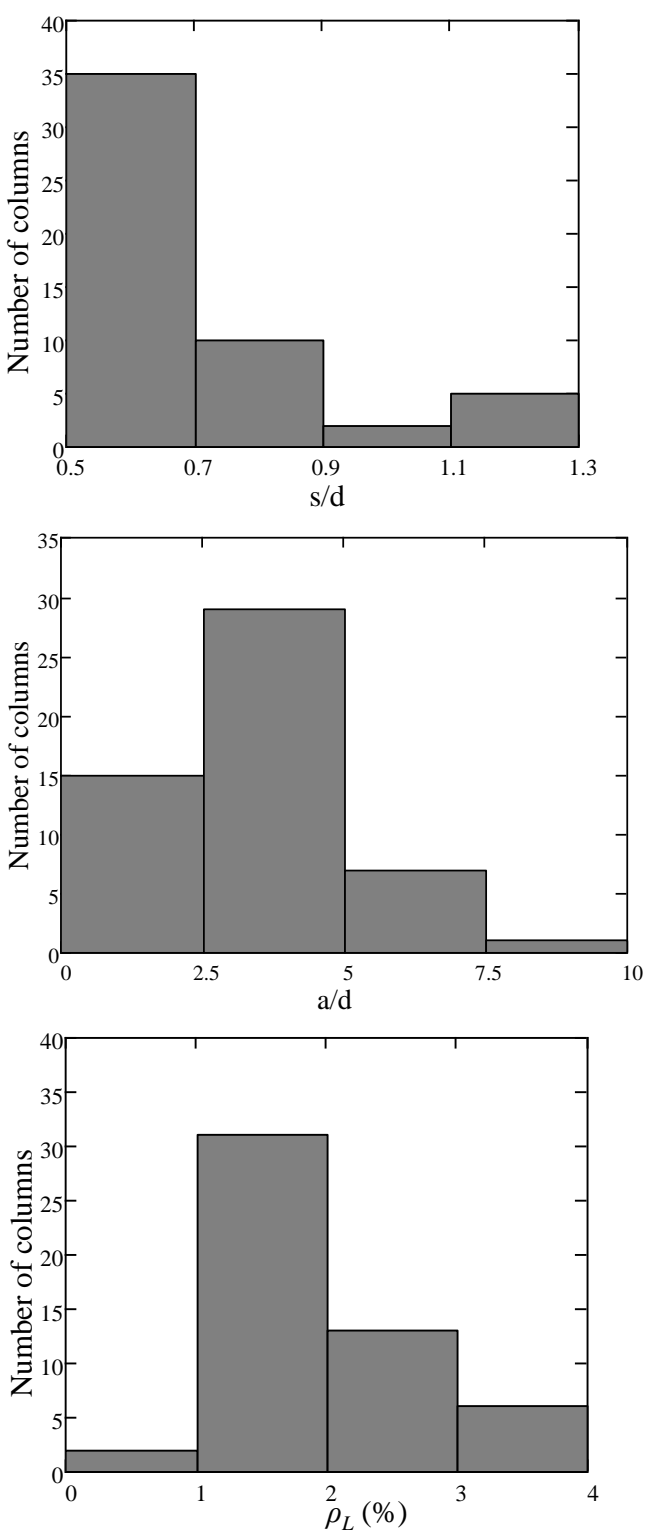
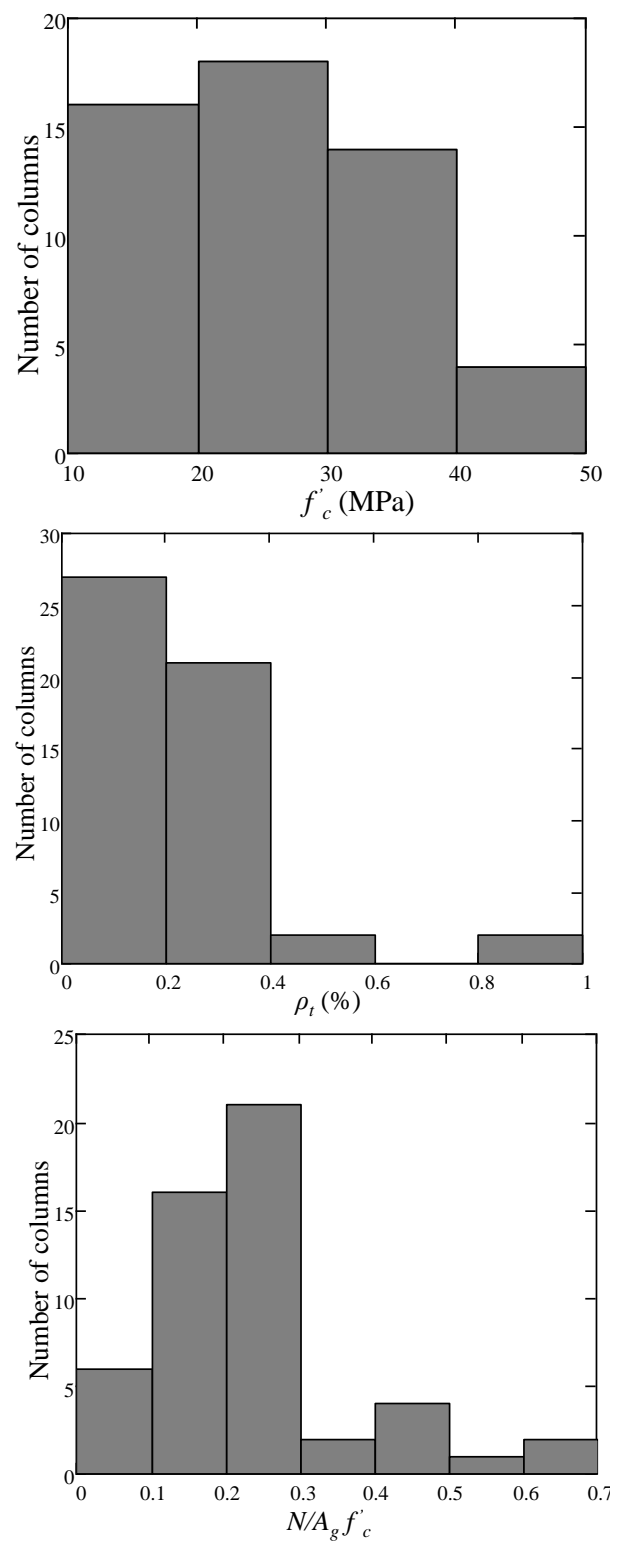

Figure 3: Properties of rectangular columns in the dataset.

\section{COMPARATIVE STUDY USING REINFORCED CONCRETE COLUMNS IN DATASET}

Following the outlined procedures in the aforementioned NZ Guideline (C5) and ASCE/SEI 41 Standards, computations of probable failure modes and deformation capacities were carried out for each of the 65 columns in the database.

\section{Comparison of Expected Failure Mode}

As indicated, ASCE/SEI 41-17 does not require the determination of the probable failure mode; however, for comparison purposes the un-degraded shear strength using Equation 4 was used in the determination of the probable failure modes based on Table 2. Output from this hybrid procedure is referred to as ASCE/SEI 41-13/17. The accuracy of C5, ASCE/SEI 41-13, and ASCE/SEI 41-13/17 in predicting probable failure modes is depicted using a matrix form below (Tables 3, $4 \& 5$ ). The green cells represents number of failure modes that were accurately predicted. The red cells and yellow cells contain failure modes that were incorrectly predicted (i.e. " 34 " in the red cell (Table 3 ) depicts number of flexure-shear critical columns that were classified as flexure-critical by C5). Yellow cells can be construed as 'conservative' (e.g. shear failure predicted, but flexural failure observed) while red cells can be construed as 'nonconservative' (e.g. flexural failure predicted but shear failure observed).

Table 3 shows that $\mathrm{C} 5$ performs very well in in the prediction of shear-critical and flexure-critical columns. However, its classification of almost all flexure-shear critical columns as flexure-critical shows a limitation in the use of the flexureshear interaction curve.

ASCE/SEI 41-13 accurately predicted most of the shear failure modes. However, most flexure-shear critical columns are conservatively predicted to fail in pure shear. Li et al. [25] have previously demonstrated the high level of conservatism in the classification of flexure-shear critical columns in ASCE/SEI 41-13 using a database of column tests from shake table experiments. 

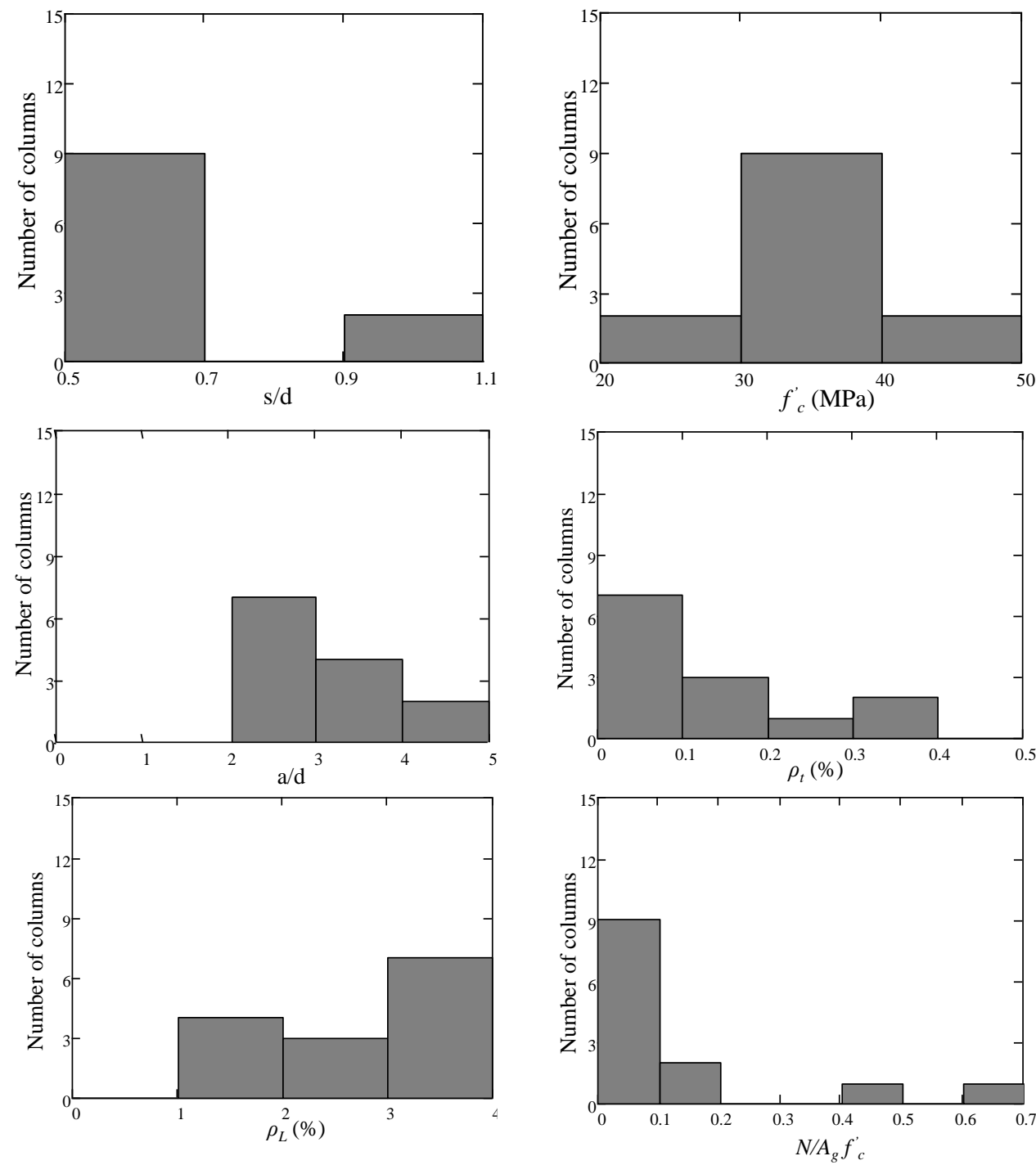

Figure 4: Properties of circular columns in the dataset.

Table 3: Comparison of experimental failure modes with predicted failure modes using $C 5$ procedure.

\begin{tabular}{|c|c|c|c|c|}
\hline & \multicolumn{3}{|c|}{ C5 } \\
\hline & & i & ii & iii \\
\hline \multirow{3}{*}{ 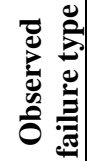 } & $\mathbf{i}$ & 11 & 0 & 0 \\
\hline & ii & 34 & 0 & 4 \\
\hline & iii & 1 & 1 & 14 \\
\hline
\end{tabular}

Condition $i$ : Flexure failure

Condition ii : Flexure-shear failure

Condition iii : Shear failure

Table 4: Comparison of experimental failure modes with predicted failure modes using ASCE/SEI 41-13 procedure.

\begin{tabular}{|c|c|c|c|c|}
\hline \multicolumn{2}{|c|}{} & \multicolumn{3}{|c|}{ ASCE/SEI 41-13 } \\
\cline { 2 - 5 } \multicolumn{2}{|c|}{} & i & ii & ii \\
\hline \multirow{2}{*}{} & i & 0 & 11 & 0 \\
\hline & ii & 0 & 12 & 30 \\
\hline 0 & iii & 0 & 1 & 15 \\
\hline 0
\end{tabular}

Table 5: Comparison of experimental failure modes with predicted failure modes using ASCE/SEI 41-13/17 procedure.

\begin{tabular}{|c|c|c|c|c|}
\hline & \multicolumn{3}{|c|}{ ASCE/SEI 41-13/17 } \\
\hline & & $\mathbf{i}$ & ii & iii \\
\hline \multirow{3}{*}{ 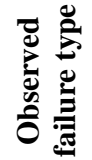 } & $\mathbf{i}$ & 0 & 11 & 0 \\
\hline & ii & 0 & 30 & 8 \\
\hline & iii & 0 & 1 & 15 \\
\hline
\end{tabular}

As previously stated, the hybrid ASCE/SEI 41-13/17 procedure was conceived in order to assess the influence of the provided shear strength equation of ASCE/SEI 41-17 (Equation 4) on predicted failure mode. A comparison between Tables 4 and 5 showed that ASCE/SEI 41-17 provides a far better estimate of the observed failure mode for the database columns. The better estimate is as a result of lower conservatism in the estimation of the contribution of transverse reinforcement to shear capacity (coefficient $\alpha_{c o l}$ ) in Equation 4, in comparison with that of ASCE/SEI 41-13 (See Equation 3) As a matter of fact, most of the eight flexureshear columns classified as shear columns by the hybrid procedure have shear capacity ratio only slightly higher than unity, thus supporting the conclusion of the Li et al. study [25] that the upper bound of shear capacity ratio for flexure-shear failure mode should be set at 1.1. Both ASCE/SEI 41-13 and 
ASCE/SEI 41-13/17 (conceived in this paper for comparison purpose) conservatively require that a column's transverse reinforcement spacing should be less than half of effective depth $(\mathrm{s} / \mathrm{d}<0.5)$ for it to be classified as flexure-governed. Since all columns in the data set have $\mathrm{s} / \mathrm{d} \geq 0.5$, the ASCE/SEI 41 Standards could not categorise any component as flexuregoverned. Considering possible variability in failure mode due to inherent material uncertainty and/or strain rate effect [30], [31], perhaps this conservatism for columns with such wide spacing of transverse reinforcement is appropriate.

\section{Comparison of Probable Deformation Capacities}

Values of $\boldsymbol{a}$ and $\boldsymbol{b}$ from ASCE/SEI 41-17,were computed using the modelling parameter equations (Equations $5 \& 6$ ). Given the significant underestimation of deformation capacity by ASCE/SEI 41-13 its implementation would result in unnecessary retrofits and hence is not considered further in this section. Plastic rotations $\boldsymbol{\theta}_{\boldsymbol{p}}$ from the C5 were calculated as follow: For shear-critical columns, $\boldsymbol{\theta}_{\boldsymbol{p}}$ equals zero, while for columns predicted to be flexure and flexure-shear critical, plastic rotations were calculated as difference between rotation at failure, using the flexure-shear interaction plot, and yield rotation, as defined previously. A comparison of computed plastic rotation at loss of lateral load, following provisions in C5 and ASCE 41-17 and measured plastic rotation is presented in Figure 5. As shown in the Figure, the C5
Guideline provides a conservative estimation of plastic rotation. The $\mathrm{C} 5$ estimation correlates to a mean ratio, defined as the mean of the ratio of measured plastic rotation to computed plastic rotation values, of 3.5.

ASCE/SEI 41-17 provides a better estimate of the median capacity from the tests. Given that the modelling parameters in ASCE/SEI 41-17 were developed based on the ACI 369 database, from which the dataset used in this study is derived, it is not surprising that the mean ratio on the estimation of $\boldsymbol{a}$ using ASCE/SEI 41-17 is 1.1.

A plot showing comparison between experimental values of plastic rotation at axial failure $(\boldsymbol{b})$ and computed values using the ASCE/SEI 41 Standards is presented in Figure 6. As shown in the plot, most of the data points fall on the unconservative side. However, as earlier stated, only eight of these columns were tested to axial failure (solid squares) and they all fall on the conservative side of the plot. Also, Ghannoum and Matamoros [26] duly noted that the assumption of drift at $25 \%$ of lateral strength as drift at axial failure provides a lower bound estimate of the experimental data, hence the results shown in Figure 6 are not unexpected.

Recall that the acceptance criteria in ASCE/SEI 41-17 are specified as a fraction of the modelling parameters $\boldsymbol{a}$ and $\boldsymbol{b}$. Hence, the acceptance criteria are more conservative than implied by Figures 5 and 6 .

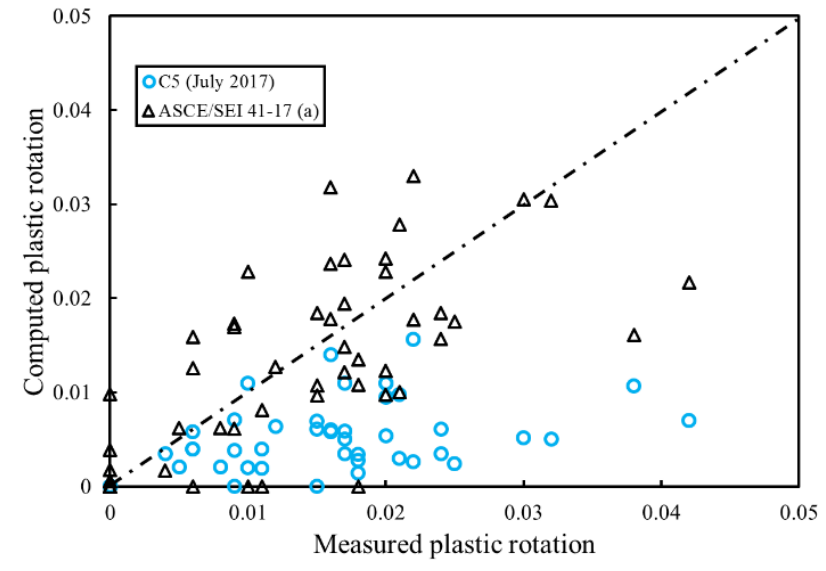

(a) Rectangular columns

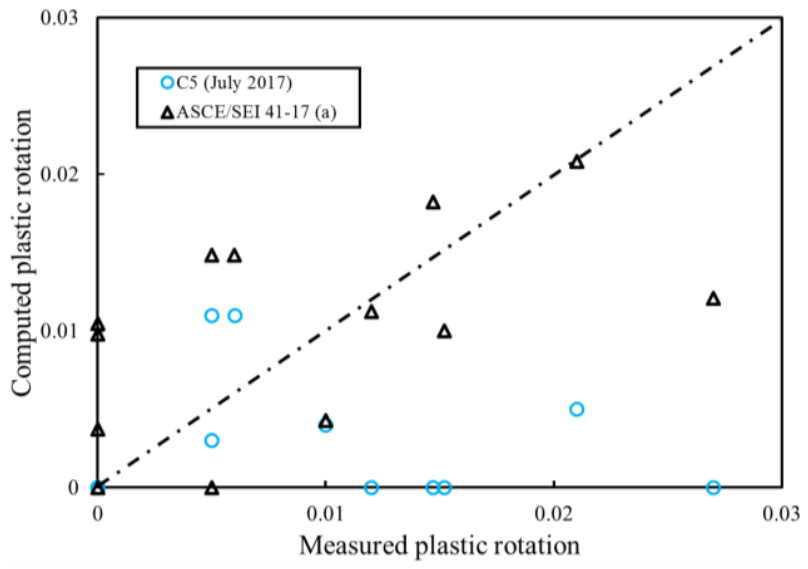

(b) Circular columns

Figure 5: Plastic rotation at loss of lateral strength.

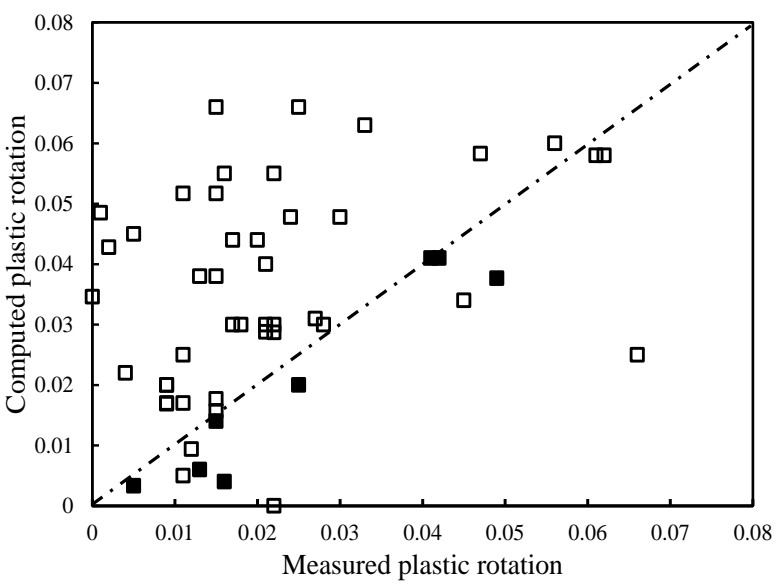

Figure 6: Plastic rotation at axial failure using ASCE/SEI 41/17. Columns tested to axial failure are marked as solid squares. 


\section{RECOMMENDATIONS}

\section{Direct Rotation Approach}

ASCE/SEI 41-17 acceptance criteria for the collapse prevention and life safety performance objectives are defined as fractions of nonlinear parameter $\boldsymbol{b}$ values. Fractions are selected to achieve a target (sufficiently low) probability of experiencing axial load failure considering the scatter in results from the modelling parameter model (Equation 6). However, to be consistent with the intent of NZ Guidelines to assess a significant life safety hazard based on loss of lateral load capacity, it is recommended to consider the acceptance criteria in NZ Guidelines as a fraction of modelling parameter $\boldsymbol{a}$ (loss of lateral load capacity), rather than modelling parameter $\boldsymbol{b}$. Figure Figure 7 indicates that using $75 \%$ of $\boldsymbol{a}$ (from Equation 5) as acceptance criteria would correspond to a probability of failure of $25 \%$ based on the dataset of nonductile rectangular columns used in this study (Figure 7). It is noted that at $0.75 a$ all high axial load cases (above $0.35 \mathrm{Ag}^{\prime}{ }^{\prime}$ ) are conservatively assessed.

The acceptance criteria is also adequate for non-ductile circular columns. (Figure 8). It is noteworthy that the three overestimated specimens have transverse reinforcement ratio less than $0.05 \%$. ASCE/SEI $41-17$ duly notes that modelling parameter equations are not applicable to such columns. Thus, for columns with very low reinforcement ratios, it is proposed that they are treated as force-controlled. For NZ Guidelines, it is recommended that for any column with transverse reinforcement less than $0.05 \%$, the plastic rotation capacity be taken as zero.

ASCE/SEI 41/17 provides a less conservative acceptance criteria for circular columns, which follows the conventional assumption that circular columns with spiral reinforcement perform better than rectangular columns with rectilinear ties. This assumption cannot be justified for lightly reinforced circular columns due insufficient data for verification, and hence is not recommended for the assessment of non-ductile circular columns in New Zealand.

In addition to providing a better estimate of deformation capacity, using $0.75 \boldsymbol{a}$ (where $\boldsymbol{a}$ is given in Equation 5) as a rotation-based acceptance criteria has the following advantages over the curvature-based method:

- Simpler to implement in practice - no need to perform moment-curvature analyses

- Less criteria to consider in assessment - 0.75a replaces limit for bar buckling, concrete crushing, and flexure-shear failure as these failure modes are implicitly considered in the limit.

- Better estimate of column failure mode by using shear model from ASCE 41-17 (see Table 5).

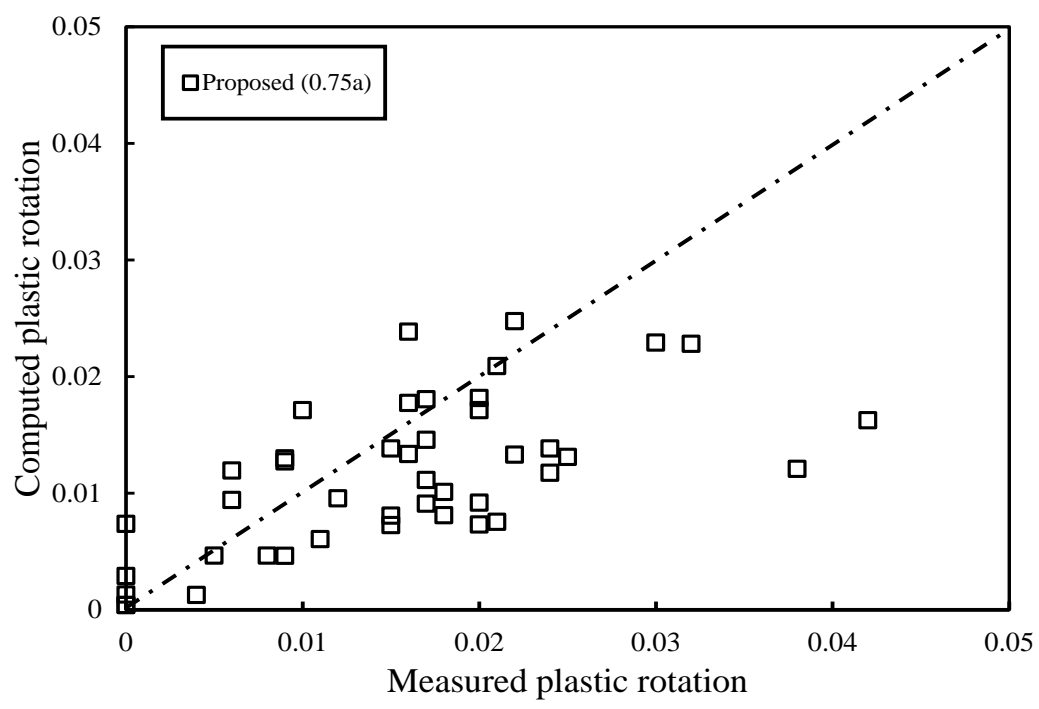

Figure 7: Proposed model for rectangular columns in the dataset.

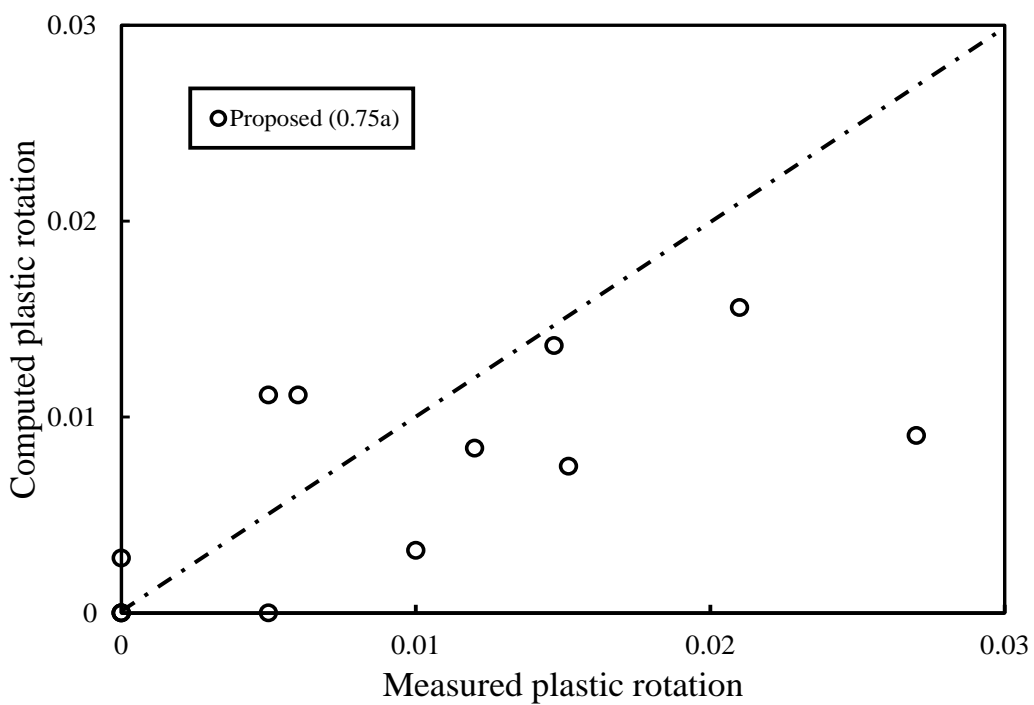

Figure 8: Plot showing adequacy of proposed model for lightly reinforced circular columns. 
In certain cases, exceeding the proposed deformation limit at loss of lateral resistance of a column, $0.75 \boldsymbol{a}$, may not significantly compromise the integrity of a building, unless the axial load capacity of the column is exceeded. For such cases, it is recommended that the Life Safety deformation limit of ASCE/SEI $41-17(0.5 \boldsymbol{b})$ be adopted as probable plastic rotation at axial failure of reinforced concrete columns. Life Safety acceptance criteria rather than Collapse Prevention is recommended since this check is done at ULS (500 year return period) demands in NZ Guidelines, rather than at MCE demands in ASCE 41-17.

The above recommendations have been incorporated as a rotation-based assessment method in an updated version of C5 currently under review by MBIE (at time of paper submission).

\section{Modification to General Curvature-Based Approach}

As noted previously in this paper, column provisions of the $\mathrm{C} 5$ July 2017 edition are unable to adequately capture probable failure mode and also under predicts the deformation capacity of the non-ductile columns in the dataset used in this study. Using a larger dataset of reinforced concrete column tests, compared to that used in developing the UCSD shear strength model, Sezen and Moehle showed that their shear strength model provides an estimate with mean ratio of 1.05 and $\mathrm{CoV}$ 0.15. As shown in Table 5, the Sezen and Moehle model adequately captures the failure mode of the columns in the dataset used in this study. Hence, it is proposed that the Sezen and Moehle shear model is adopted in C5, similar to ASCE/SEI 41-17.

An improved level of conservatism in the prediction of deformation capacity using the general curvature-based approach can be achieved by modifying the plastic hinge length limit and the definition of unconfined conditions used in C5. It is proposed that the plastic hinge length should be limited to a minimum of $2 L_{s p}$ (Priestley et al 2007). It was noted, for the columns in the dataset used in this study, that the $2 L_{s p}$ limit improves deformation capacity estimation by $40 \%$, on average.

Furthermore, for the estimation of $\varepsilon_{c, \text { max. }}$ it is proposed that the unconfined condition be assumed only if any of the following are present:

- transverse reinforcement spacing greater than half of the element's effective depth and 12 times diameter of longitudinal reinforcement

- transverse reinforcement spacing greater than 16 times diameter of longitudinal reinforcement

- tie hooks are not properly anchored in the core (i.e. 90 degree hooks)

- only corner longitudinal bars are restrained by a bend of transverse reinforcement.

When compared against the July 2017 version summarised previously under Computation of Probable Flexural Strength and Deformation Capacity, the only change is to add the condition in the first bullet that the transverse reinforcement must also be greater than 12 times the diameter of the longitudinal reinforcement.

A comparison of deformation limits provision by the C5 July 2017 edition and proposed provisions is presented in Table 6 .

\section{CONCLUSIONS}

This study has assessed the proposed acceptance criteria for concrete columns in C5 of NZ Guidelines, and compared these limits with limits in ASCE/SEI 41 and data from cyclic tests 52 rectangular and 13 circular concrete columns similar to

secondary 'gravity' columns found in pre-1995 buildings in New Zealand. The following conclusions are made:

- Compared to the ASCE/SEI 41 assessment procedures, the C5 curvature-based procedure is time consuming;

- The July 2017 C5 curvature-based procedure predicts most columns will experience flexural failures, when in fact flexure-shear failures are observed in tests;

- July 2017 C5 curvature-based procedure, in comparison with ASCE/SEI 41-17, results in a more conservative deformation limit relative to performance of the column tests considered in this study;

- ASCE/SEI 41 provides a simple estimate of the plastic rotation at lateral load failure, a, with a mean ratio of 1.1 while the July 2017 C5 curvature-based procedure provides estimates with a mean ratio of 3.5 , based on the selected database.

Based on the results of this study, it is recommended to use $0.75 \boldsymbol{a}$, where $\boldsymbol{a}$ is based on Equation 5 , as a rotation-based acceptance criteria for concrete columns in C5 of the NZ Guidelines. Modifications to criteria for definition of unconfined conditions and plastic hinge limit of the curvaturebased procedure are also proposed to provide a better estimate of the deformation capacity of non-ductile concrete columns.

\section{NOTATION}

$a$

$\mathrm{A}_{\mathrm{c}}$

$\mathrm{Ag}_{\mathrm{g}}$

$A_{s}$

$\mathrm{A}_{\mathrm{v}}$

$\boldsymbol{b}$

$b_{\mathrm{w}}$

c

$\mathrm{cu}$

d

d" or h"

$\mathrm{h}_{\text {min }}$

$\mathrm{d}_{\mathrm{b}}$

$\mathrm{d}_{\mathrm{s}}$

$\mathrm{D}$

k

$\mathrm{K}_{\mathrm{ebb}}$

$\mathrm{kd}$

L

$\mathrm{L}_{\mathrm{c}}$ or a

$\mathrm{L}_{\mathrm{p}}$

$\mathrm{m}$

$\mathrm{M}$

$\mathrm{M} / \mathrm{Vd}$

M/VD

$\mathrm{M}_{\mathrm{y}}$

$\mathrm{N}$ or $\mathrm{P}$

$\mathrm{s}$ or $\mathrm{S}_{\mathrm{h}}$

$\mathrm{V}_{\mathrm{n}}$
Modelling parameter representing the plastic rotation at incipient lateral-strength degradation; Area of concrete core of section measured to outside of peripheral hoop,

Gross area of section

Total area of longitudinal reinforcement

Transverse reinforcement area within a spacing, s, in the loading direction

Modelling parameter representing the plastic rotation at incipient axial degradation

Column section width

Modeling parameter representing the residual lateral strength of a column

Neutral axis depth at ultimate capacity

Primary effective depth of the longitudinal tension reinforcement

Depth of concrete core

Least lateral dimension of cross section

Diameter of longitudinal reinforcement

Diameter of transverse reinforcement

Column section depth

Coefficient that accounts for spread of plasticity

due to tension-shift effects $k=0.2\left(\frac{f_{u}}{f_{y}}-1\right) \leq$ 0.08

Transverse reinforcement coefficient

Neutral axis depth at first yield

Clear height of column

Shear span of column

Plastic hinge length

$\mathrm{fy}_{\mathrm{y}} /\left(0.85 \mathrm{f}^{\prime} \mathrm{c}\right)$

Ultimate moment capacity of column section

Ratio of applied moment to applied shear times the effective depth and is bounded by the values of 4 and 2

Ratio of applied moment to applied shear times full depth of column

Moment at first yield

Axial load

Transverse reinforcement spacing

Shear strength enhancement provided by axial compression 
Table 6: Comparison of deformation limits, from C5 July 2017 edition and proposed deformation limits, with experimental results. (Note: Shear-critical components have plastic rotation of zero and have thus been omitted from these plots).

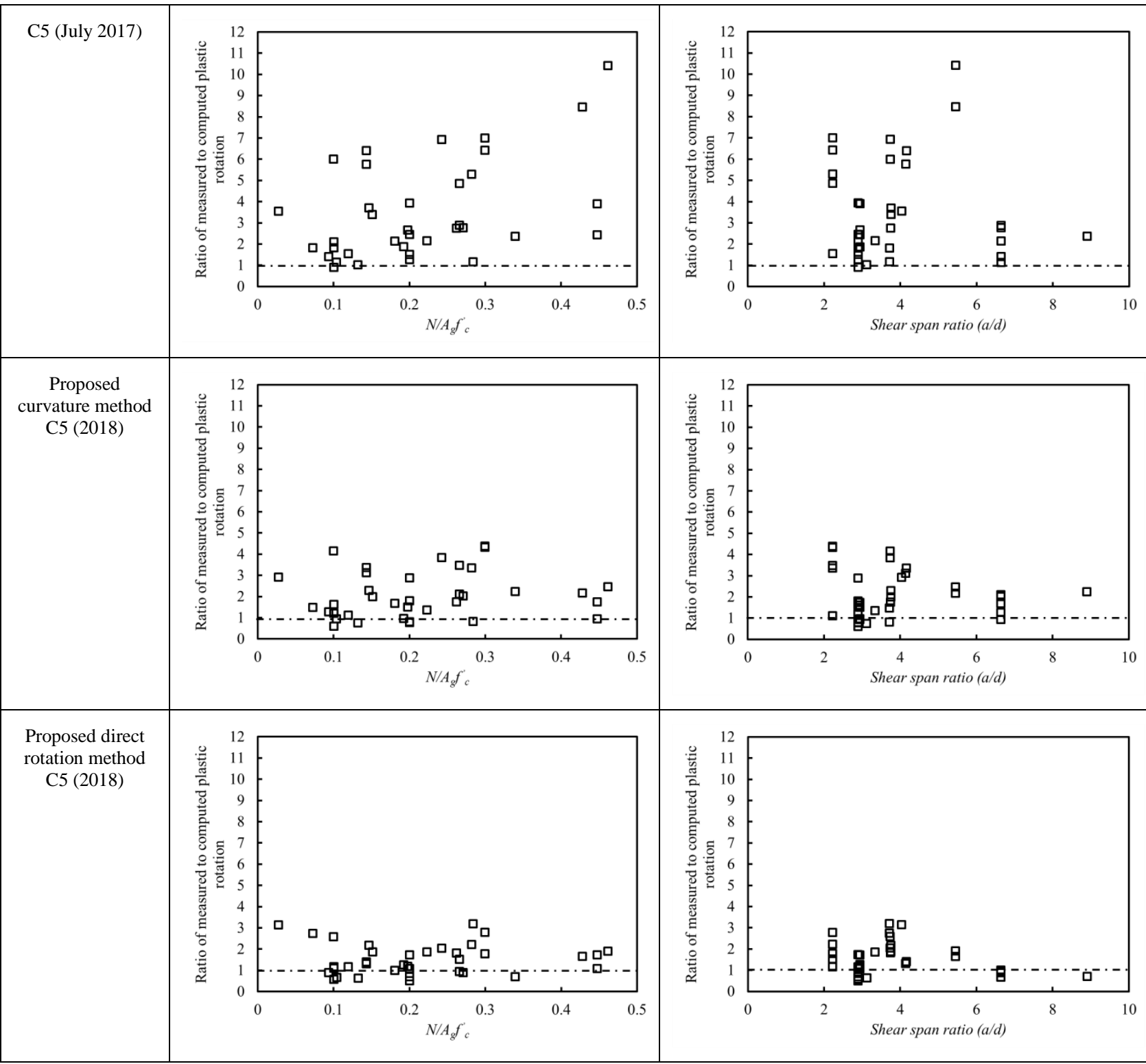

$\mathrm{V}_{\mathrm{f}} \quad$ Shear demand at flexural strength (Noted as $\mathrm{V}_{0}$ in $\quad \phi$ ASCE $/$ SEI 41) $=\mathrm{M} / \mathrm{L}$

$V_{\text {prob }} \quad$ Probable shear strength capacity

$\mathrm{V}_{\mathrm{prob}(0)} \quad$ Probable un-degraded shear strength (Noted as $\mathrm{V}_{\mathrm{p}}$ in ASCE/SEI 41)

$\mathrm{V}_{\mathrm{s}} \quad$ Shear contribution from transverse reinforcement

$\alpha \quad$ Angle the diagonal compression strut and the longitudinal axis of the column

$\alpha_{c} \quad$ Coefficient that accounts for the column aspect ratio

$\alpha_{\text {col }} \quad$ Factor for adjusting transverse reinforcement contribution to shear capacity

$\beta \quad$ Modifier that accounts for longitudinal steel ratio

$\gamma \quad$ Shear strength degradation factor

$\Delta_{s} \quad$ Displacement at shear failure

$\Delta_{\mathrm{u}} \quad$ Displacement at onset of bar buckling

$\varepsilon_{\mathrm{cu}} \quad$ Ultimate strain in extreme concrete fibre

$\varepsilon_{\mathrm{y}}^{\prime} \quad$ Strain at first yield

$\varepsilon_{y} \quad$ Strain at yield

$\theta_{\mathrm{p}} \quad$ Probable plastic rotation

$\theta_{\mathrm{u}} \quad$ Probable ultimate rotation

$\theta_{\mathrm{y}} \quad$ Probable yielding rotation

$v \quad$ Maximum nominal shear stress
Strength reduction factor, according to NZS 3101:1982

$\varphi_{y}^{\prime} \quad$ Probable first yield curvature

$\varphi_{\mathrm{y}} \quad$ Probable yield curvature

$\varphi_{\mathrm{u}} \quad$ Probable ultimate curvature

$\mathrm{f}_{\mathrm{c}} \quad$ Concrete compressive strength

$\mathrm{f}_{\mathrm{u}} \quad$ Longitudinal reinforcement ultimate strength

$f_{y} \quad$ Longitudinal reinforcement yield strength

$\mathrm{f}_{\mathrm{yt}} \quad$ Transverse reinforcement yield strength

$\rho_{\mathrm{L}} \quad$ Longitudinal reinforcement ratio: area of longitudinal reinforcement divided by gross crosssectional area of column $\left(\mathrm{A}_{\mathrm{s}} / \mathrm{Ag}_{\mathrm{g}}\right)$

$\rho_{\mathrm{t}} \quad$ Transverse reinforcement ratio: area of transverse reinforcement, in direction of primary load spaced, at $\mathrm{s}\left(\mathrm{A}_{\mathrm{v}} / \mathrm{b}_{\mathrm{w}} \mathrm{s}\right)$

\section{REFERENCES}

1 Department of Building and Housing (2012). "Technical Investigation into the Structural Performance of Buildings in Christchurch - Final Report". Department of Building and Housing, Wellington, NZ.

2 NZ Guideline (2017). "Part C5, Concrete Buildings, 
Technical Guidelines for Engineering Assessments". http://www.eq-assess.org.nz

3 American Society of Civil Engineers (2007). "Seismic Rehabilitation of Existing Buildings: ASCE/SEI 41-06". American Society of Civil Engineers, Roston, VA.

4 American Society of Civil Engineers (2014). "Seismic Evaluation and Retrofit of Existing Buildins: ASCE Standard ASCE/SEI 41-13". American Society of Civil Engineers, Reston, VA.

5 American Society of Civil Engineers (2017). "Seismic Evaluation and Retrofit of Existing Buildings, Standard ASCE/SEI 41-17". American Society of Civil Engineers, Reston, VA.

6 FEMA-273 (1997). "NEHRP Guidelines for the Seismic Rehabilitation of Buildings". Federal Emergency Management Agency, USA.

7 FEMA-356 (2000). "Prestandard and Commentary for the Seismic Rehabilitation of Buildings". Federal Emergency Management Agency, USA.

8 Elwood KJ, Matamoros AB, Wallace JW, Lehman DE, Heintz JA, Mitchell AD, Moore MA, Valley MT, Lowes LN, Comartin CD and Moehle JP (2007). "Update to ASCE/SEI 41 Concrete Provisions". Earthquake Spectra, 23(3): 493-523.

9 Ghannoum WM (2017). "Updates to modeling parameters and acceptance criteria for non-ductile and splice-deficient concrete columns". 16 ${ }^{\text {th }}$ World Conference on Earthquake Engineering, Santiago, Chile, Paper No 1010.

10 Holliday L and Grant H (2011). "Haiti building failures and a replicable building design for improved earthquake safety". Earthquake Spectra, 27(1).

11 Sezen H, Elwood KJ, Whittaker AS, Mosalam KM, Wallace JW and Stanton JF (2000). "Structural Engineering Reconnaissance of the August 17, 1999, Kocaeli (Izmit), Turkey, Earthquake". PEER Technical Report No. 2000.9.

12 Kam WY, Pampanin S and Elwood K (2011). "Seismic performance of reinforced concrete buildings in the 22 February Christchurch (Lyttelton) earthquake". Bulletin of the New Zealand Society for Earthquake Engineering, 44(4): 239-278.

13 Cubrinovski M, Pampanin S and Bradley B (2013), "Geotechnical and Structural Aspects of the 2010-2011 Christchurch (New Zealand) Earthquakes". In: Garevski M. (eds) Earthquakes and Health Monitoring of Civil Structures. Springer Environmental Science and Engineering. Springer, Dordrecht, pp. 1-35.

14 Niroomandi A, Pampanin S and Dhakal RP (2015). "The History of Design Guidelines and Details of Reinforced Concrete Column in New Zealand". Annual Conference of the New Zealand Society for Earthquake Engineering, Rotorua, NZ.

15 Elwood KJ and Moehle JP (2005). "Axial capacity model for shear-damaged columns". ACI Structural Journal, 102(4): $578-587$.
16 Sezen H and Moehle JP (2004). "Shear strength model for lightly reinforced concrete columns". Journal of Structural Engineering, 130(11): 1692-1703.

17 Kowalsky MJ and Priestley MJN (2000). "Improved analytical model for shear strength of circular reinforced concrete columns in seismic regions". ACI Structural Journal, 97(3): 388-396.

18 Paulay T and Priestley MJN (1992). "Seismic Design of Reinforced Concrete and Masonry Buildings". John Wiley and Sons, New York. p. 765.

19 Priestley MJN, Calvi GM and Kowalsky MJ (2008). "Displacement-Based Seismic Design of Structures". IUSS Press, Pavia, Italy.

20 Priestley MJN, Verma R and Xiao Y (1994). "Seismic Shear Strength of Reinforced Concrete Columns". Journal of Structural Engineering, 120(8): 2310-2329.

21 Ascheim M and Moehle JP (1992). "Shear Strength and Deformability of $R C$ Bridge Columns Subjected To Inelastic Displacements". Earthquake Engineering Research Center, University of California.

22 Watanabe F and Ichinose T (1991). "Strength and ductility design of RC members subjected to combined bending and shear". Proceedings of Workshop on Concrete in Earthquake, pp. 429-438.

23 Elwood KJ and Moehle JP (2005). "Drift Capacity of Reinforced Concrete Columns with Light Transverse Reinforcement". Earthquake Spectra, 21(1): 71-89.

24 Berry MP and Eberhard MO (2005). "Practical Performance Model for Bar Buckling". Journal of Structural Engineering, 131(7): 1060-1070.

25 Ghannoum WM and Sivaramakrishnan B. "ACI 369 Column Database: Network for Earthquake Engineering".

$26 \mathrm{Li} \mathrm{Y,} \mathrm{Elwood} \mathrm{KJ} \mathrm{and} \mathrm{Hwang} \mathrm{S} \mathrm{(2014).} \mathrm{"Assessment} \mathrm{of}$ ASCE/SEI 41 Concrete Column Provisions using Shaking Table Tests". ACI Special Publication 297, pp 1-22.

27 Sheikh SA and Yau G (2002). "Seismic behavior of concrete columns confined with steel and fiber-reinforced polymers". ACI Structural Journal, 99(1): 72-80.

28 Liu J and Sheikh SA (2013). "Fiber-reinforced polymerconfined circular columns under simulated seismic loads". ACI Structural Journal, 110(6): 941-951.

29 Ghannoum WM and Matamoros AB (2014). "Nonlinear Modeling Parameters and Acceptance Criteria for Concrete Columns". ACI Special Publication No. 1, pp. 124.

30 Hernanto E (2005). "Seismic Assessment of Pre-1970s Reinforced Concrete Structure". Master of Engineering Thesis, Department of Civil and Natural Resources Engineering, University of Canterbury, p. 247.

31 Mutsuyoshi $\mathrm{H}$ and Machida A (1985). "Behavior of Reinforced Concrete Members Subjected to Dynamic Loading". Transactions of JSCE, V(6): 51-68. 


\section{APPENDIX A}

A flow chart of the C5 procedure for estimating probable failure mode and deformation capacity of reinforced concrete columns is presented below. A general summary of this presented in Figure A1. Figures A2 and A3 present procedures for estimation of flexural strength, flexural drift capacity and shear strength respectively. Figure A4 shows typical flexure-shear interaction curves for probable failure modes of secondary 'gravity' reinforced concrete columns

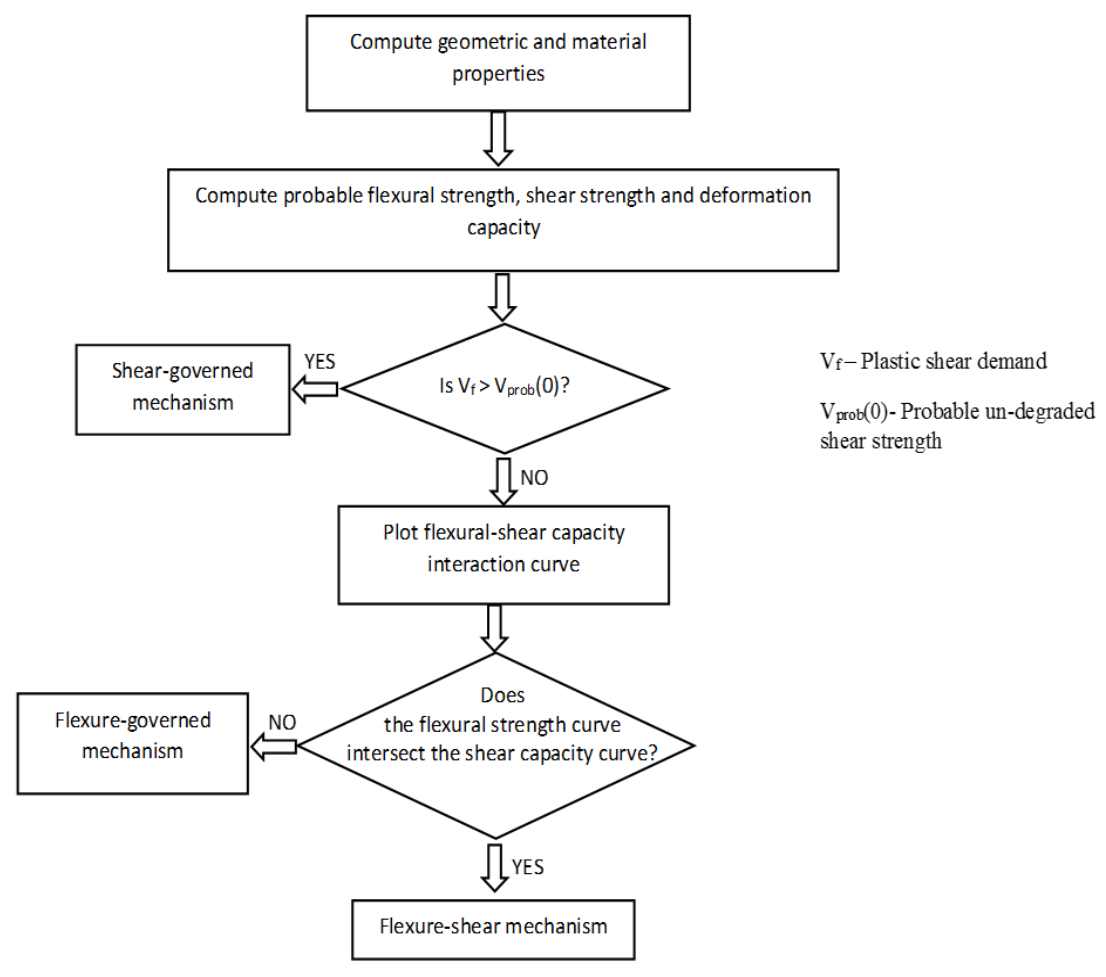

Figure A1: Summary of C5 procedure for computation of probable failure mode and deformation capacity.

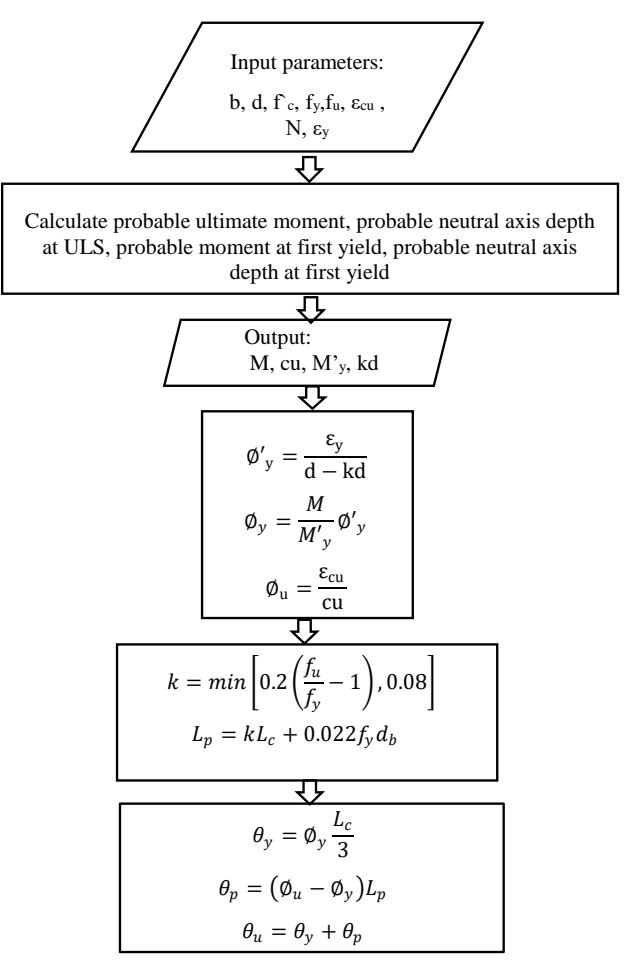

Figure A2: Computation of flexural strength and drift capacity.

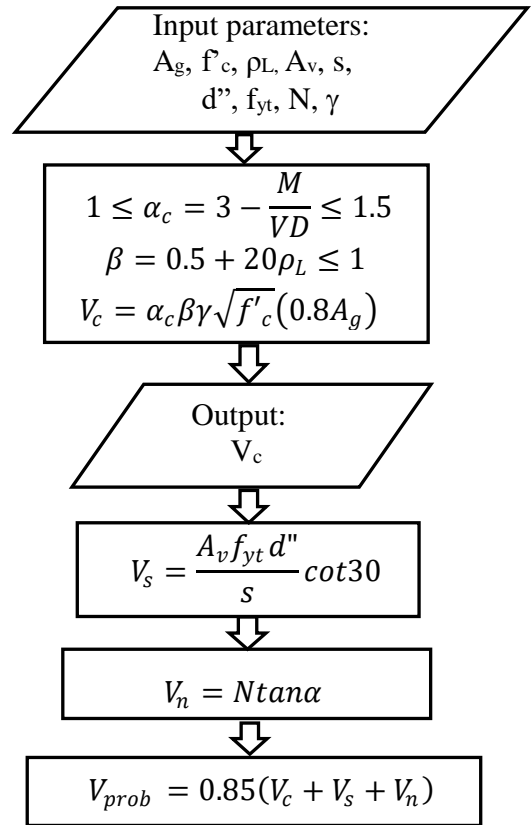

Figure A3: Computation of shear strength. 
(a)

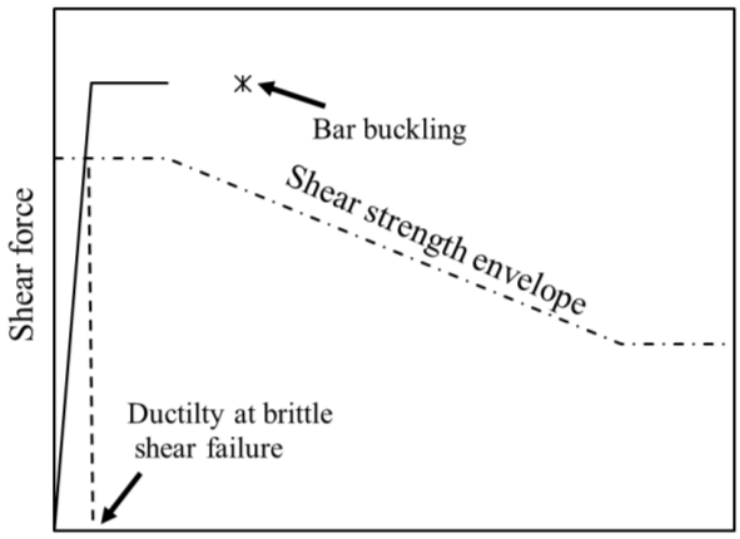

Ductility demand

(c)

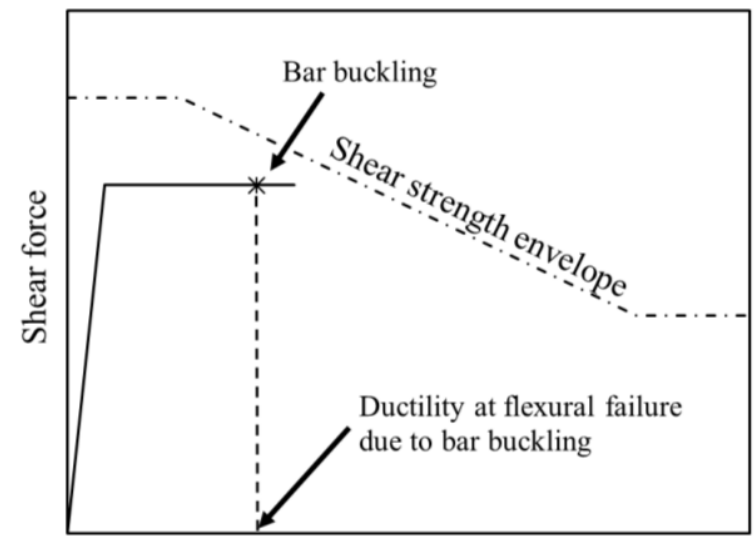

Ductility demand (b)

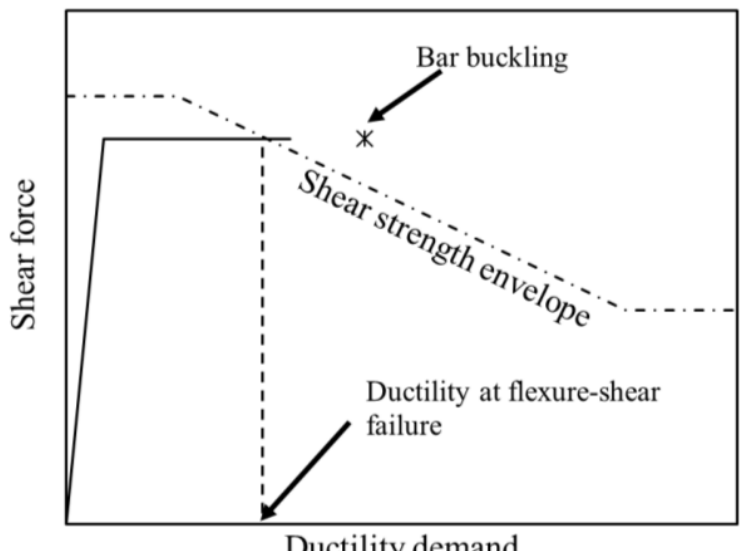

(d)

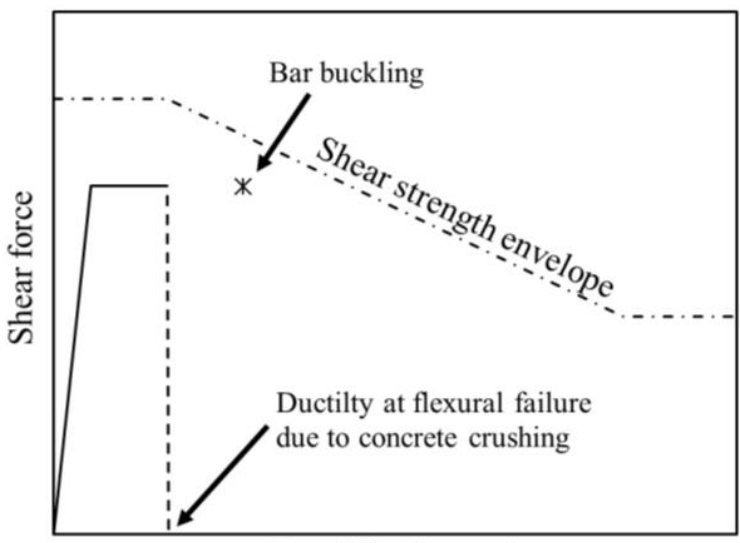

Ductility demand

Figure A4: Flexure-shear interaction curves based on C5: (a) brittle shear failure; (b) flexure-shear failure; (c) flexure failure due to bar buckling; (d) Flexure failure due to concrete crushing. 